Portland State University

PDXScholar

1971

\title{
Evidence for the existence of two stable sites for cobalt impurity atoms in aluminum
}

Arun Venkatachar

Portland State University

Follow this and additional works at: https://pdxscholar.library.pdx.edu/open_access_etds

Part of the Atomic, Molecular and Optical Physics Commons, Condensed Matter Physics Commons, and the Materials Chemistry Commons

Let us know how access to this document benefits you.

\section{Recommended Citation}

Venkatachar, Arun, "Evidence for the existence of two stable sites for cobalt impurity atoms in aluminum" (1971). Dissertations and Theses. Paper 1477.

https://doi.org/10.15760/etd.1476

This Thesis is brought to you for free and open access. It has been accepted for inclusion in Dissertations and Theses by an authorized administrator of PDXScholar. Please contact us if we can make this document more accessible: pdxscholar@pdx.edu. 


\section{AN ABSTRACT OF TIE TIESIS OF Arun Venkatachar for the}

Master of Science in Physics presented August 17, 1971.

Title: Evidence for the Existence of Two Stable Sites for Cobalt Impurity Atoms in Aluminum.

APPROVED BY THE MEMBERS OF TUE TIESTS COMMTTTEE.

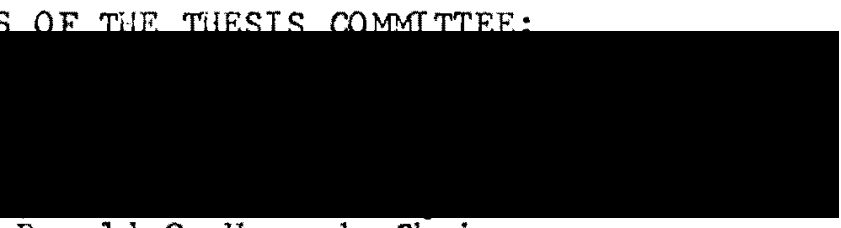

Donald G. Howard, Chairman

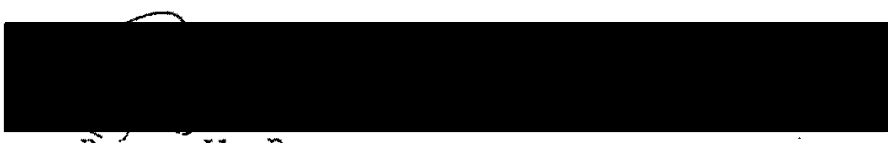

Bruce W. Brown

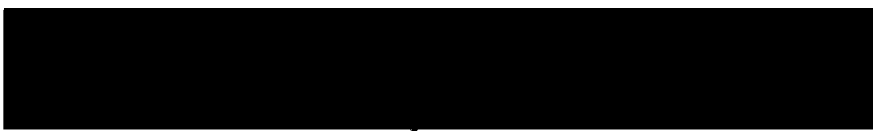

Rudi H. Nuss baum

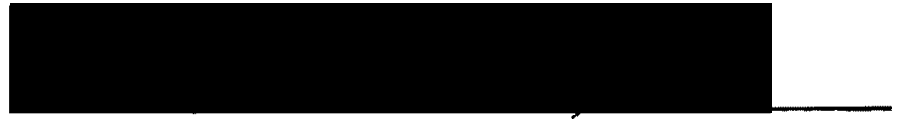

Raymond W. Somerfeldt

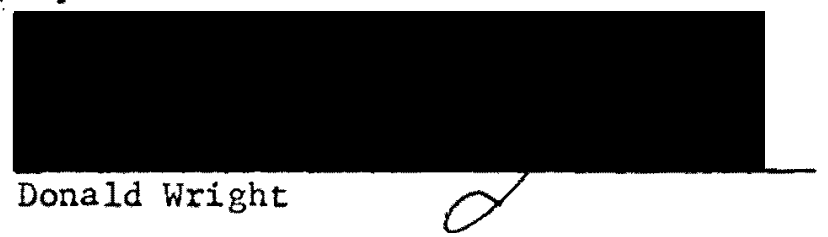

Using $\mathrm{Fe}^{57}$ Mössbauer spectroscopy, two alternative sites occupied by cobalt $\left(10^{-4}\right.$ at. \%) impurity atoms in aluminum have been isolated. The substitutional site A is the stable position after annealing the sample above $840 \mathrm{~K}$, followed by a rapid quench. The impurity atoms in site A are characterized by a 
single line Mossbauer spectrum (indicative of a cubic environment), a room-temperature $f=0.502$ (r.m.s. displ. $0.071 \mathrm{~A}$ ) and an I. S. (rel. to $\mathrm{Fe})=-0.421 \mathrm{~mm} / \mathrm{sec}$. For anneals below $770 \mathrm{~K}$ the cobalt atoms migrate to site $B$, which is characterized by a well resolved quadrupole doublet (Indicative of a non-cubic environment), a large change in the value of the room-temperature $f=0.766($ r.m.s. displ. $0.071 \mathrm{~A})$, I. S. $=-0.150 \mathrm{~mm} / \mathrm{sec}$ (increased s-electron density at the nucleus). All linewidths are approximately $0.21 \mathrm{~mm} / \mathrm{sec}$, indicating high uniformity of impurity sites. The site distribution [A] / [B] varies from about $5 \%$ to $95 \%$ for anmeals between $770 \mathrm{~K}$ and $830 \mathrm{~K}$. 
EVDENCE FOR THE FXISTENCE OF TWO STABLE SITES FCQ COBALT IMPURTSY AMCHS $7 T$ ATIMINTM

\section{ARUT VENKATACHAR}

A thesis submitted in partial fulficlment of the requirements for the degree of

MASTEX OF SCIENCE

in

PHYSICS

Portiend state Oniversicy August j.or1. 
TO TIE OFFIC OF GRADUATE STUDIES:

The nembers of the Committes approve the thesis of Arun Venkatachar presented Ausust 17, 1971.

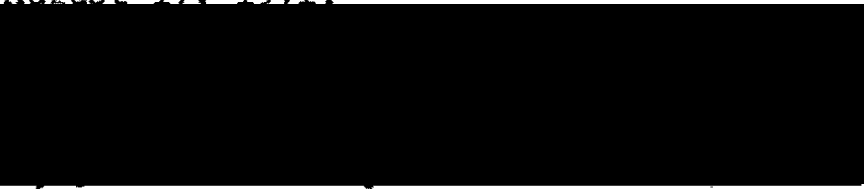

Donald G. Howard, Chairman

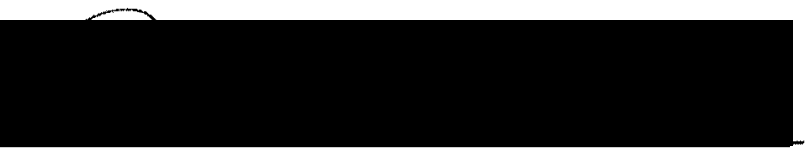

Bruce W. Brown

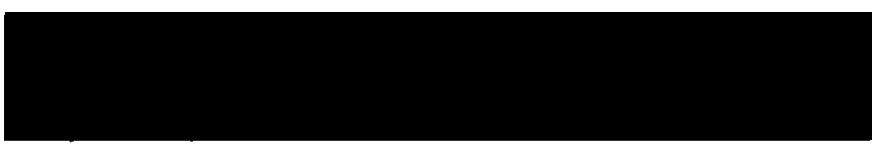

Rudi H. Nussbaum

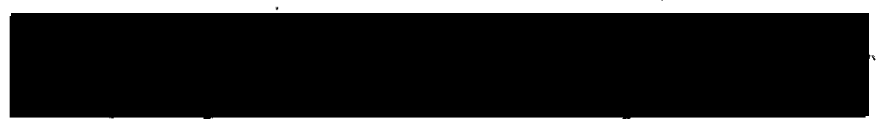

Raymond W. Sommerfeldt

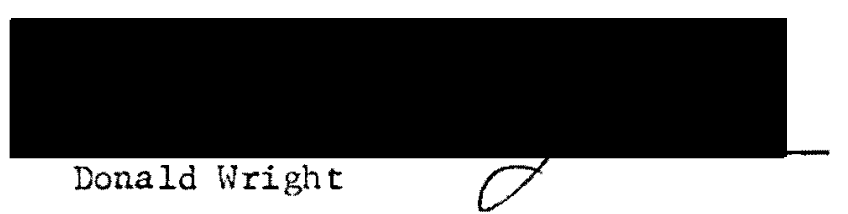

APPROVED:

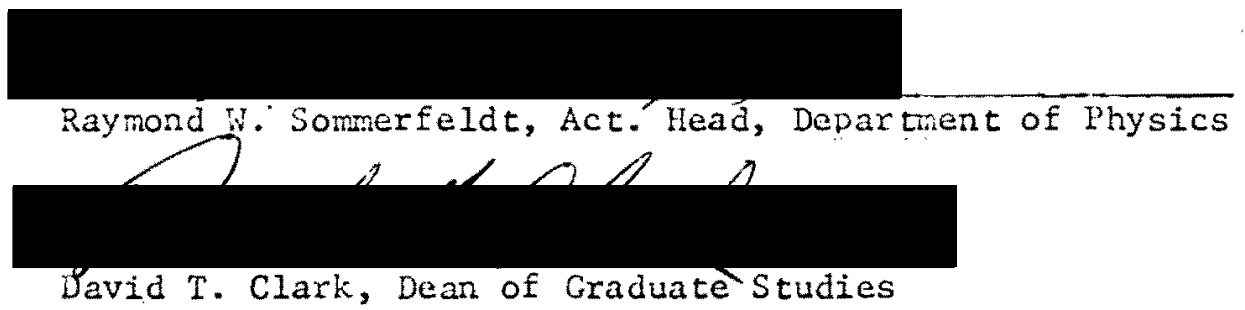

August 17, 1971 


\section{ACKNOWLEDGENENTS}

Wie author wishes to express his leep apreciation to the inspiration, guidance, and assistance riven by Professors

Howard end russbaum. The authos is copecialiy indebted to

Mrs Barbara Elbling for her effort in typing this thesis. Lastly, I wish to thank NSF for the finarcial assistence which made this investigation possible. 
MABLE OF CONTENSS

PAGE

ACKTOWLEDGEVENTS . . . . . . . . . . . . .

LIST OF TABLES . . . . . . . . . . . . . .

LIST OF FIGURES . . . . . . . . . . . . . . .

\section{CHAPTER}

I INTRODUCTION ................

II REVIEW OF LITERATURE . . . . . . . . .

III THEORY . . . . . . . . . . . . .

Debye-waller factor . . . . . . . .

Line shapes . . . . . . . . . . . .

IV EXPRTMENTAL . . . . . . . . . . . . .

Source Preperation .............

Annealing Frocedure . . . . . . . . .

Iine Shape Mecsurements ...........

Pebre-Wajler factor Measurements . . . . .

$v$ DATA PRESENTATYON AIHD INTERPRETATION . . . .

site $A \ldots \ldots \ldots \ldots$

24

site $\mathrm{E} \ldots \ldots \ldots \ldots \ldots$

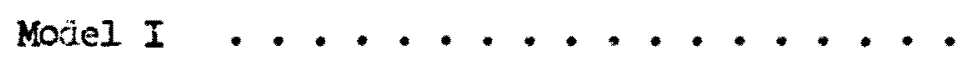

Model II .............. 


\section{LIST OF TABLES}

TABLE

PAGE:

I Comparison of Parameters derived from Iine Shape Measurements Reviewed in Chapter I. . . . . . 6

II Iine Shape and Lattj.ce Dynamical Parameters for Iron Atoms occupying Site A . . . . . . . . 27

III Line Shape and Lattice Dynamical Parameters for Iron Atoms occupying site B .......... 31

IV Summary of Data for sites $A$ and $B$ occupied by $C^{57}$

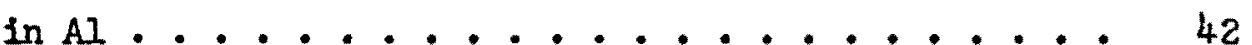


1 Isomer shift ................... 15

2 Quadrupole Splitting ............... . 15

3 Magnetic Hyperfine Splitting . . . . . . . . 15

4 Energy Spectrum of $\mathrm{Fe}^{57}$ in $\mathrm{AI} . . . . . . . . . . .20$

5 Temperature dependence of the Debye-Waller factor for Co atoms in Sites A and B . . . . . . . . . 22

6 Time dependence of the Debye-Weller factor for Fe

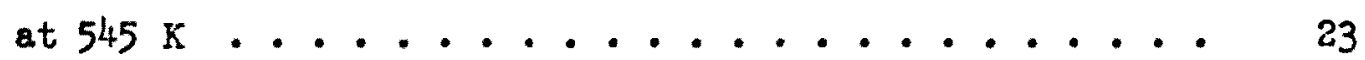

7 Mössbauer spectrum for $\mathrm{Co}^{57}$ atoms occupying site A . . . 25

8 Mössbauer Spectrum for co ${ }^{57}$ atoms occupying site B . . . 29

9 Temperature dependence of $\mathrm{K}(\mathrm{T})$............. 33

10 Mössbauer Spectrum taken after annealing AI II at $793 \mathrm{~K}$ for 3 days ...................... 34

11 Position of the impurity Dumbbell in the Al lattice . . 36

12 Electrostatic Potential per unit positive charge about an Co atom in an AI matrix .......... 38 


\section{INTRODUCTION}

A crystal can act very much like a rigid body insofar as at least a fraction of low energy ganma rays are enitted or absorbed by a radioactive atom (embedied in the crystal) in a recoil - free fashion; that is, essentially wthout any energy loss, since the crystal as a whole takes up the recoil moinentum. This phenomenon is called the Mössbauer effect and the probability for a recoiless emission (or absorption) is commonly referred to in the 1iterature as the Lamb-Mössbauer or Debye-Waller factor ' $f$ '.

A number of investigators $(1-6)$ have utilised the Mössbauer effect to study dilute alloys of $\mathrm{Fe}^{57}$ (and its parent $\mathrm{Co}^{57}$ ) in aluminum. There exists a general lack of agreement in the results of their investigations. The main purpose of this thesis was to re-examine the Co-Al system using not only Mössbauer line shapes (as used by previous workers) but also precision f-measurements. We have found that a combination of these two techniques can yield more information than just using line shape data.

As a result of our investigations, we have found that at very low concentrations $\left(1.0^{-4}\right.$ at. \% Co), cobalt atoms occupy two distinct sites In the linst lattice. Co atoms in site $A$ are characterised by a cubic environment and a low room-temparature $f(=0.502)$. On the other hand, site $B$ is characterised by a non-cubic environment and a much higher 
room-temperature $f(=0.766)$. In addition, using $f$-measurements we have followed the transformation of co atoms from one site to the other, both as a function of time as well as temperature. These measurements have been useful in determining the nature of site $B$. This thesis is divided into three sections: the first section contains the theory, where a brief analysis of the Debye-Waller factor is given. The Influence of internal fields on line shapes has also been discussed in this section. In the experimental section, the emphasis is on the alloy preperation and the annealing procedure used. The third and final section contains the presentation and interpretation of data. 


\section{REVIEW OF LITERATURE}

The earliest paper pertalning to the use of the Mössbauer effect in studying dilute alloys of Iron in Aluminum is that due to Bara et al (1). The source used by Bara and his co-workers was a foll of Al on which was deposited $\mathrm{Co}^{57}$ In the form of an aqueous solution of $\mathrm{Co}^{57} \mathrm{Cl}_{2}$. The sample was then diffused at $873 \mathrm{~K}$ in an argon atmosphere for 100 minutes. A room temperature line shape measurement on the source revealed that the spectrum consisted of a single line pattern. After further diffusion at the same temperature, the room temperature spectrum changed with the single line growing weaker and the gradual appearance of a six line, magnetically split pattern. The authors interpreted the six ifne pattern as the result of long paramagnetic spin relaxation times assoclated with an extremely dilute solution of magnetic iron Impurity in a non-magnetic host lattlce. Next, they studied the temperature variation of the hyperfine spectrum and found that at $573 \mathrm{~K}$ the six line pattern completely disappeared and only a doublet remained. They considered this to be a quadrupole doublet and attributed its formation to a structural change in the sample. Sprouse and Kalvius (2) used a Mössbauer source prepared by introducing coulomb excited $\mathrm{Fe}^{57}$ nuclei into an $\mathrm{Al}$ foll by the technique of recoil implantation. The Mössbauer spectrum measured at room temperature conststed of a broad single line pattern. The 
broadening was attributed to an unresolved quadrupole coupling in the crystal.

Besides the above menticned scurce experiments, work has also been done with absorbers nade of dilute alloys of iron in aluminum. Bush et al (3) used a 0.05 wt \% alloy (made by melting $39.999 \%$ pure $\mathrm{Al}$ and $\mathrm{Fe}$ containing $68 \% \mathrm{Fe}^{57}$ ) for their experiments. The Mössbauer spectrum taken after annealing the sample at $913 \mathrm{~K}$ for a perlod of 65 hours was found to be a single line pattern. Next, they annealed the sample for 128 hours at $593 K$ and found that the Mössbauer spectrum had changed to a quadrupole doublet. They attributed the single line to be characteristic of a substitutional solid solution of Fe in Al and the doublet pattern to be the result of iron precipitating out of the solid solution. In addition, they showed that contrary to phase diagrara studies the precipitate did not correspond to $\mathrm{FeAl}_{3}$ but was Indeed a true preclpitate of iron. They have suggested a distorted f.c.c. structure for the preclpitate.

Janot and Lelay (4) working with dilute alloys (0.006-0.24 wt \% of Fe in A1) as absorbers have been able to isolate two precipitate phases in addition to the solid solution phase mentioned above. Both these preclpitates are characterised by quadrupole effects visible in their Mössbauer spectra. They have found a 'plate like' precipltate is formed by cold-working the sample prior to annealing it at $593 \mathrm{~K}$. The 'rod like' precipltate was formed by heat treating the sample at $723 \mathrm{~K}$ for 13 hours.

Nasu et al (5) measured the shift of the solid solution 
line as a function of temperature, and from this they calculated how much of the total shift relative to metallic fron is due to thermal shift and how much 1 s due to the isoner shift.

Recently, Preston and Gerlach (6) have measured the Mössbauer spectra of dilute alloys of Fe in $A l$ with the iron concentration rangling between 0.005 and $1.2 \%$. The spectrum analysis reveals the presence of two phases- a solid solution phase similar to that obtained by previous workers, and a multiple line component which they interpret to be the result of $\mathrm{Fe}^{57}$ in $\mathrm{Fe}_{4} \mathrm{Al}_{13^{\circ}}$. They have found that these two phases can be easily distinguished from each other by the difference in their behaviour when either the concentration or temperature is varied. 
TABLE I

COMPARISON OF PARAMETERS DERIVED FROM LINE SHAPE MEASUREMENTS REVIEWED IN THIS SECTION

\begin{tabular}{|c|c|c|c|c|}
\hline Component & $\begin{array}{l}\text { Isomer Shift } \\
\text { ' } \delta \text { ' } \\
(\mathrm{mm} / \mathrm{sec})\end{array}$ & $\begin{array}{l}\text { Quad. } \\
\text { Splitting } \\
' \Delta E^{\prime} \\
(\mathrm{mm} / \mathrm{sec})\end{array}$ & $\begin{array}{c}\text { Line Wldth } \\
\text { ' }{ }^{\prime} \\
(\mathrm{mm} / \mathrm{sec})\end{array}$ & Reference \\
\hline Single Line & $\begin{array}{l}-0.310 \\
-0.440 \\
-0.423 \\
-0.424 \\
-0.430 \\
-0.422\end{array}$ & $\begin{array}{l}- \\
- \\
- \\
-\end{array}$ & $\begin{array}{l}0.800 \\
0.660 \\
0.250 \\
0.280 \\
0.250 \\
0.242\end{array}$ & $\begin{array}{l}\mathrm{a}, 1 \\
\mathrm{~b}, 2 \\
\mathrm{c}, 3 \\
\mathrm{~d}, 4 \\
\mathrm{e}, 5 \\
\mathrm{f}, 6\end{array}$ \\
\hline $\begin{array}{l}\text { Quadrupole Sp11t } \\
\text { Line }\end{array}$ & $\begin{array}{l}-0.740 \\
-0.140\end{array}$ & $\begin{array}{l}0.320 \\
0.270\end{array}$ & $0 . \overline{260}$ & $\begin{array}{l}a, 1 \\
c, 3\end{array}$ \\
\hline $\begin{array}{l}\text { Ppt. Phase I } \\
\text { Ppt. Phase II }\end{array}$ & $\begin{array}{l}-0.100 \\
-0.200\end{array}$ & $\begin{array}{l}0.200 \\
0.300\end{array}$ & $\begin{array}{l}0.280 \\
0.350\end{array}$ & $\begin{array}{l}d, 4 \\
d, 4\end{array}$ \\
\hline $\begin{array}{l}* \star \\
\mathrm{Fe}_{4} \mathrm{Al}_{13}\end{array}$ & $\begin{array}{l}-0.010 \\
-0.202 \\
-0.392\end{array}$ & 0.382 & $\begin{array}{l}0.265 \\
0.265 \\
0.265\end{array}$ & f. 6 \\
\hline
\end{tabular}

All Isomer shifts quoted in table are with respect to natural iron. ** This spectra was fitted by using three lines of equal width and line positions given in column 2 of table.
a) Bara et ai, Phys. Status Solidi 17, K 53 (1966)
b) Sprouse et a1
c) Bush et a1 Scripta Met. 1, 75 (1967)
d) Janot and Lelay, Compt. Rend. 269B, 823 (1969)
e) Nasu et a1, J. Phys. Soc. Japan 27, 1363 (1969)
f) Preston and Gerlach 
iii. THEORY

\section{Debye-Waller Factor}

Consider the emission of a gamma ray from a radioactive nucleus embedded in a crystal. Due to the strength and short range nature of the nuclear forces an assumption (7) can be made that the nuclear decay is not influenced by the state of the lattice and the lattice conditions in turn do not depend on the nuclear state. Under these conditions, we can write the matrix element describing the transition In which a gamma ray of momentum $\mathrm{kK}$ is emitted by the nucleus whose center of mass coordinate is $x$, while the lattice goes from an intitial state $L_{1}$ to some final state $L_{f}$, as a produce of two matrix clements (7).

1) $M_{L}=\left\langle L_{1}\left|e^{1 K \cdot X}\right| L_{f^{\prime}}\right\rangle\langle N\rangle$

The transition probability $\mathrm{P}\left(\mathrm{L}_{1} \longrightarrow \mathrm{L}_{\mathrm{f}}\right)$ is proportional to the square of the above matrix element and has been shown by LIpkin (8) to have the form:

2) $\quad P\left(L_{1} \longrightarrow L_{f}\right)=\left.\left|<L_{1}\right| e^{I K \cdot X}\left|L_{f}\right\rangle\right|^{2}$

The Mössbauer effect arises if during the nuclear transition there is no simultaneous lattice transition. For such a transition $L_{1}=L_{f}$, and the gamma ray is enitted recollessly. The probability for a Mössbauer transition (or the Debye-Waller factor), f, will be: 
3) $f=\left.\left|<L_{i}\right| e^{1 K \cdot x}\left|L_{1}\right\rangle\right|^{2}$

For a crystal with harmonic forces the Debye-Waller factor $f$ takes a simple form (7):

4) f $-\exp \left(4 \pi<x^{2}>/ \lambda^{2}\right)$

where $\left\langle x^{2}\right\rangle$ is the time averaged mean squared displacement of the Impurity atom along the direction of gamma ray emission, and $\lambda$ is the wave length of the gamma quantum. Equation (4) describes $f$ to a high degree of accuracy, Including the case where the atom is an 1mpurity vibratiug in localized mode (9). For harmonically bound crystals the mean squared displacement is related to the phonon frequency spectrum $G_{h}(\omega)$ in a mono-atomic crystal (15), while for an impurity atom $G_{1}(\omega)$ stands for the "dynamic response function", (15) which describes the coupling of the Impurfty modes to the unperturbed normal modes of the host. In that case $G_{1}(\omega)$ also depends on the impurity-host mass ratio and it may also include localized vibrational modes (15).

5) $\left\langle x^{2}\right\rangle=\frac{\hbar}{m} \int_{0}^{\infty} \operatorname{coth}(\hbar \omega / 2 k T) G(\omega) / \omega d \omega$ where $G(\omega)$ is normalized: $\int_{0}^{\infty} G(\omega) d \omega=1$

At high temperatures $\left(\hbar \omega / \mathrm{kT}_{\mathrm{T}}<2 \pi\right), \operatorname{coth}(\hbar \omega / \mathrm{kT})$ in equation (5) can be expanded:

6) $\left\langle\mathrm{x}^{2}\right\rangle=\frac{\mathrm{kT}}{\mathrm{m}} \int\left[1+\frac{1}{12}\left(\frac{\hbar \omega}{\mathrm{kT}}\right)^{2}-\frac{1}{720}\left(\frac{\hbar \omega}{\mathrm{ET}}\right)^{4}+\ldots\right] \frac{\mathrm{G}(\omega)}{\omega^{2}} \mathrm{~d} \omega$ Using the moments of the frequency spectrum defined as $\omega^{n}=\int_{0}^{\infty} G(\omega) \omega^{n} d \omega$ 
we can write the high temperature limit as follows:

7) $\left\langle x^{2}\right\rangle=\frac{k}{m}\left[\overline{\omega^{-2}} \mathrm{~T}+\frac{1}{12}\left(\frac{k}{k}\right)^{2} \mathrm{~T}^{-1}-\frac{1}{720}\left(\frac{\hbar}{\mathrm{k}}\right)^{4} \overline{\omega^{2}} \mathrm{~T}^{-3}+\ldots\right]$

Each term in the above expansion can be described in terms of an effective Debye frequency spectrum such that its nth moment $\omega_{D}(n)$ equals the real moment $\omega^{n}$. The $\omega_{D}(n)$ defines weighted Debye temperatures $\theta_{D}(n)$ according to:

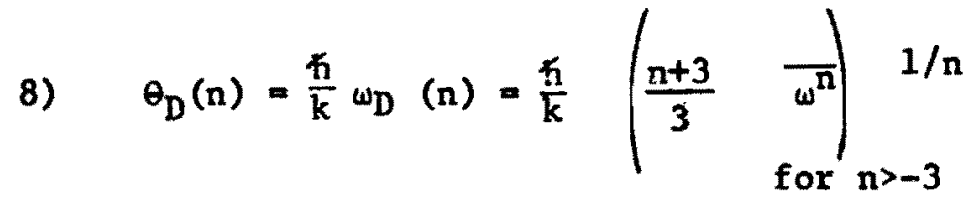

From equations (7) and (8) we find that at high temperatures and for harmonic forces:

9) $-\ln f_{h}=\frac{6 R T}{K}\left(\frac{1}{\theta_{D}(-2)}\right) 2\left[1+\left(\frac{\theta_{D}(2)}{6 T}\right)^{2}+\ldots\right]$ The first term contributes more than $95 \%$ for $T / \theta_{D}<0.72$, We therefore see that high temperature $f$ measurements yield the lattice parameter $\theta_{D}(-2)$.

So far, we have assumed that the forces present in the crystal are harmonic, while in fact all crystals have some inherent anharmonicity. Marradudin and Flinn (10) have shown that as a result of high temperature anharmonicity, we have the expression:

10) $\ln f=\ln f_{h} \quad[1+\varepsilon(-2) T]$

where $f_{h}$ is the harmontc Mössbauer fraction and $E(-2)$ is the anharmonicity parameter at high temperatures. 


\section{LINE SHAPES}

The gamma ray enitted is not monochromatic, but has an intensity distribution which is Lorentzian in character and is given by the expression:

11) $I(E)=\frac{\Gamma^{2} / 4}{\left(E-E_{0}\right)^{2}+\Gamma^{2 / 4}}$

$E_{0}$ is the energy of the nuclear transition; $\Gamma$ is the natural width of the emission band and is equal to the full width at half maximum of the above Lorentzian line shape. From Heisenberg's uncertainty principle, $I$ can be related to $\tau$, the mean 11fe time of the decaying nucleus, by the relationship:

12) $\quad \Gamma=\frac{h}{\tau}$

Wertheim (12) has shown that for thin absorbers, the experimentally determined Mössbauer spectrum which is $\mathrm{a}$ result of the folding of the absorption and emission lines, is also Lorentzian in shape with a line width equal to the sum of the line widths of the absorption and enission lines. If both these lines have natural line widths, the Mössbauer line width is fust twice the line width of the gamma ray. Natural line widths are rare in Mössbauer research, as varlous factors such as source and absorber thickness, velocity resolution of apparatus, internal fields, etc., broaden and change the 
shape of the line.

Due to the narrow line width of the nuclear transition involved In the Mössbauer effect, resonant absurption is extremely sensitive to energy of the gamma radiation. For this reason small interactions between the nucleus and orbital electrons, which cannot be observed directly by other methods, manifest themselves very markedly in the Mössbauer effect. It is thus the influence of the electronic environment on the nuclear transition, both in emission and abscrption that determines the hyperfine structure of the Mössbauer spectrum. The main interactions that reveal themselves in the Mössbauer effect are:

a) Nuclear Isomer shift

b) Nuclear quadrupole coupling

c) Magnetic hyperfine interactions

The nuclear isomer shift is the nuclear analogue of two hyperfine interactions observed in the electronic spectrum: the isotope shift and the isomeric shift. These effects are changes in wavelength of spectral terms of different isotopes and in the isomeric states of one and the same isotope. The nuclear 1somer shift, which manifests itself as a shift from zero velocity of the centrold of the Mössbauer spectrum, is due to the electrostatic interaction between the charge distribution of the nucleus and those electrons which have a non-vanishing probability in the region occupled by the nucleus. An expression (12) can be derived for this interaction between the nuclear charge and the electronic charge: 
13) $E_{s}=\frac{2 \pi}{3} \mathrm{Ze}^{2}|\psi(0)|^{2}\left[\left\langle\mathrm{R}^{2}\right\rangle \mathrm{ex}-\left\langle\mathrm{R}^{2}\right\rangle \mathrm{gr}\right]$

where $e|\psi(0)|^{2}$ is the electronic charge density, $z$ the atomic number for the Impurity atom $\left\langle R^{2}\right\rangle_{g r} \&\left\langle R^{2}\right\rangle_{e x}$ the mean squared radil for the ground and exclted states reopectively (see figure 1). The experimental quantity measured in the Mössbauer effect is the difference (see equation 12) between a source characterlzed by a given electron density $\left|\psi_{s}(0)\right|^{2}$ and an absorber characterized by a different electron density $\left|\psi_{a}(0)\right|^{2}$. Thus :

14) $\delta E=Z e^{2}\left[\left\langle R^{2}\right\rangle_{e x}-\left\langle R^{2}\right\rangle_{g r}\right]\left|\psi_{a}(0)\right|^{2}-\left|\psi_{s}(0)\right|^{2}$

The nuclear isomer shift is always measured as a relative quantity, and is expressed as a product of a nuclear factor and an electronic one.

The nuclear quadrupole coupling results in an interaction of the nuclear quadrupole moment $Q$ with the gradient of the electric field due to the other charges present in the crystal. The contribution to field gradient comes from three sources:

a) Charges external to the impurity atom; the ionic charges of the lattice may produce a fleld gradient at a given atomic site.

b) Electrons belonging to the atom; example: in transition fons the inner d or f shells are not completely filled and may cause an electric fleld gradient at the nucleus.

c) Polarization of the Inner shells of the atom; the filled inner shells have spherical symetry and 
normally give no contribution to the field gradiant. However, both external charges outside the atom and its own unpalred aiectrons can polarize these Inner shells, which then wili contribute to the field gradient at the nucleus.

For the $14.4 \mathrm{kev}$ transition $\mathrm{in} \mathrm{Fe}^{57}$ the ground and exited states are characterized by spins $3 / 2$ and $1 / 2$. In the presence of an electric field gradient the excited level is split into two sub-levels (see f1gure 2). The Mössbauer spectrum w111 consist of two components corresponding to the transitions: $\pm 3 / 2 \longrightarrow 1 / 2$ and $\pm 1 / 2 \longrightarrow 1 / 2$. If there is an electric field of cubic symetry acting on the emitting nucleus there will be no field gradient and only one line in the Mössbauer spectrum corresponding to the transitton $3 / 2 \rightarrow 1 / 2$. On the other hand, a non-zero electric fleld gradient indicates a departure from cublc symmetry and the spectra will consist of two components.

The magnetic hyperfine interactions arise due to the effective magnetic fleld acting on the nucleus. The main contributions to the field are :

a) The Fermi contact Interaction: direct coupling between the nucleus and unpaired s-electron density.

b) The contribution of the orbital magnetic moment.

c) Dipole interaction with the electronic spin. Werthe1m (12) has shown that in the case of the $14.4 \mathrm{kev}$ transition in $\mathrm{Fe}^{57}$, six different transitions (see figure 3 ) are possible if the 
Iron nucleus is acted upon by a magnetic fleld. Therefore, in the natural Iron absorber (comonly used for line shape measurements) the spectrum is split into six completely rasolved lines of natural width. 

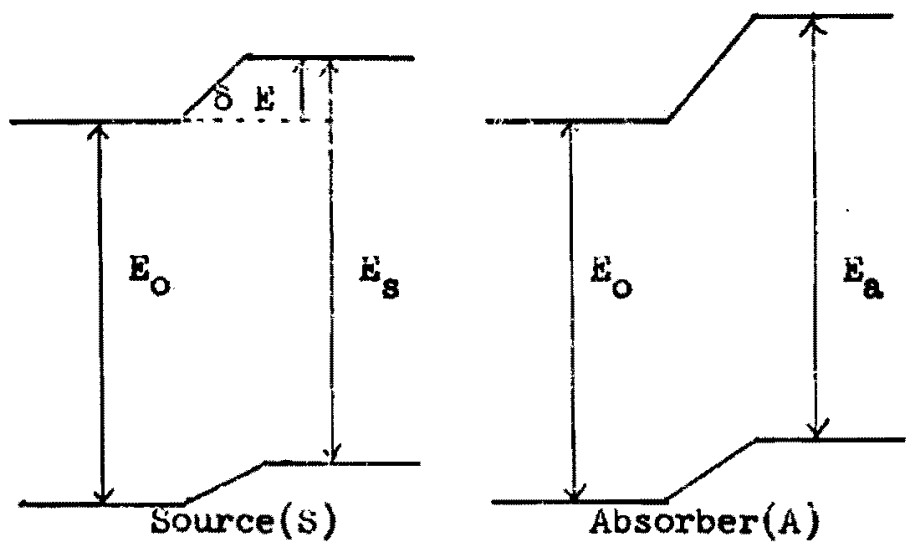

Figure 1. Isoner shift

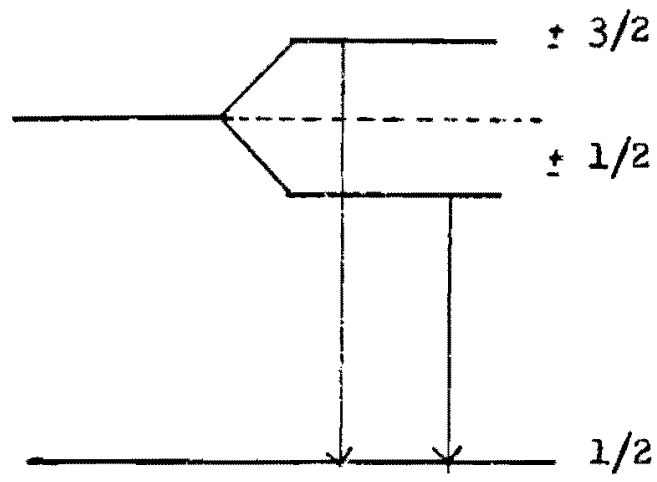

Figure 2. Quadrupole splitting in $\mathrm{Fe}^{57}$

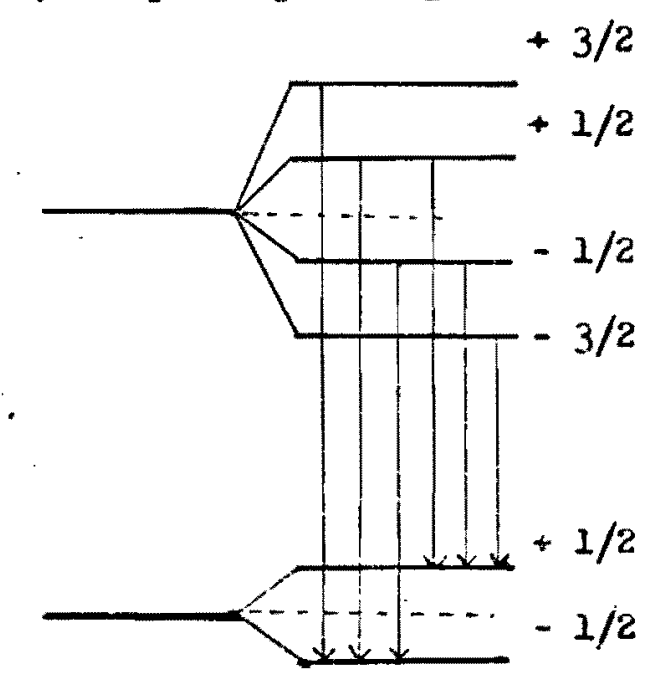

Figure 3. Magnet1c hyperfine splitting 


\section{EXPERIMFNTAL}

\section{Source Preparation}

A piece of Aluminum was cut with a jeweler's saw from a single crystal of $99.999 \%$ purity obtained from Semi-Metals Inc. This piece was rolled into a foll of thickness $0.35 \mathrm{~mm}$. A small rectangular ( $8 \mathrm{~mm} \times 6 \mathrm{~mm}$ ) plece was cut from this foll and the surface degreased with tri-chloroethylene. The foil was then dropped into a test tube contalning a $1 \mathrm{~N}$ solution of $\mathrm{NaOH}$ so as to dissolve as much of the oxide $\left(\mathrm{Al}_{2} \mathrm{O}_{3}\right)$ layer as possible. The foll was then washed with distilled water to remove all traces of the alkali. After allowing the surface to dry a small amount of beef-albumin was deposited on the Al surface. The albumin serves as a wetting agent. Next approximately $1.5 \mathrm{mill1-curies}$ of activity in the form of $\mathrm{CoCl}_{2}$ in $0.1 \mathrm{~N}$ HCl was pipetted onto the metal surface. The activity was measured by placing the foil under a Nal scintillation counter and determining the count rate of the $122.0 \mathrm{kev}$ gamma ray, then comparing this count rate with that for a $\mathrm{Cu}$ source with known activity concentration.

The foll was then placed on a small quartz plate and gently Introduced Into a quartz tube closed at one end. The tube was then Inserted Into a furnace heated to about $898 \mathrm{~K}$ and the source diffused In an atmosphere of hydrogen for 3 days. The hydrogen atmosphere serves two maln purposes: reduces $\mathrm{CoCl}_{2}$ to metallic Cobalt and 
secondly prevents the Al surface from getting oxidized. A line shape was taken after this initlal heat treatment and the results of this measurement indicated that the sample required additional diffuston. The source was put back in the furnace at the same temperature and the diffusion process continued for another week. For the second diffuston we placed the system under vacuum $\left(10^{-4} \mathrm{~mm}\right.$ of $\mathrm{Hg}$ ). The high vacuum served as an added precaution against oxidation of the sample. The diffusion temperature and time were chosen after a careful study of the solubility of Co in Al (26). After the completion of this second diffusion, the sample was removed and scrubbed with pumice soap and then etched with $1 \mathrm{~N} \mathrm{NaOH}$ solution. This removes all traces of activity left on the surface. The count rate from the foil was measured again and 1 t was found that there was about 0.8 milli-curies of activity associated with the source (Al II).

\section{Annealing Procedure}

The annealing of the Al source was carried out in a Lindberg high temperature tube furnace. Silicon Carbide heating elements are used to heat the furnace. These elements cross the heating chamber at right angles with closer spacing at the chamber ends then at the center. This arrangement of the elements gives a uniform heat distribution in the chamber. The fumace is capable of operating in the temperature range $773 \mathrm{~K}$ to $1773 \mathrm{~K}$. The sample is placed in the above mentioned quartz tube and fintroduced in the furnace. The tube is $69 \mathrm{~cm}$. In length and $1.8 \mathrm{~cm}$. In diameter. The annealing was 
carried out in an atmosphere of hydrogen. The temperature of the source was measured by means of a chronel-alumel thermo couple placed in the heating chamber of the furnace. The tube was so positioned that the sample lay as close to the thermo couple as possible. The temperature fluctuations in the furnace were in the order of $\pm 2 \mathrm{~K}$. The quenching of the source was carried out by plunging the tube into a large beaker containing cold water.

\section{LIne Shape Measurements}

Mơsbauer line shape measurements Involve the determination of the counting rate of the gamma radiation emitted by a source and passing through an absorber as a function of the instantaneous Doppler velocity of the source. This is achieved by using the speaker drive described by Nees (12). The absorber used in measuring 1ine shapes with Al II was natural Iron - a $7.6 \mathrm{mg} / \mathrm{cm}^{2}$ foll of Iron containing a natural abundance $(2 \%)$ of $\mathrm{Fe}^{57}$. Due to the nuclear Zeeman effect mentioned in the theory section of this thesis, the Mössbauer spectrum will consist of six well resolved 11nes. of these six IInes, only the inner two closest to zero velocity have been used by us.

\section{Debye-Waller Factor Measurements}

The Debye-Waller factor $f$ was measured both at room temperatures and elevated temperatures using the black, wide absorber technique (1). The experimental value of $f$ has to be corrected for:

a) Re-radiation fron the black absorber 
b) Blackness of the black absorber.

c) Fintte amount of resonant absorption at $I_{\infty}$.

Besides these corrections, one has to make an additional correction for the Compton scattering from the Berylium window in the furnace used for high temperature $f$ measurements. These corrections as well as the experimental set up used has been described in detall by Housley (14).

Due to the low Atomic number of Al there are no host x-rays of energy comparable to the $14.4 \mathrm{kev}$ gamma ray. An energy spectrum was taken for the sample, using an $X_{e}-\mathrm{CH}_{4}$ filled proportional counter, an FET preampliffer and a 512 multi-channel pulse helght analyzer. The spectrum (see Fig. 4) shows two well resolved peaks corresponding to the $14.4 \mathrm{kev}$ gamma ray and $6.3 \mathrm{kev} \mathrm{K}_{\alpha} \mathrm{x}$-ray of Iron. Thus, no additional corrections have to be made for the presence of the host $x-r$ ays. Using the corrections discussed in this sub-section, we have found the statistical accuracy for f-measurements to be better than $0.5 \%$. 


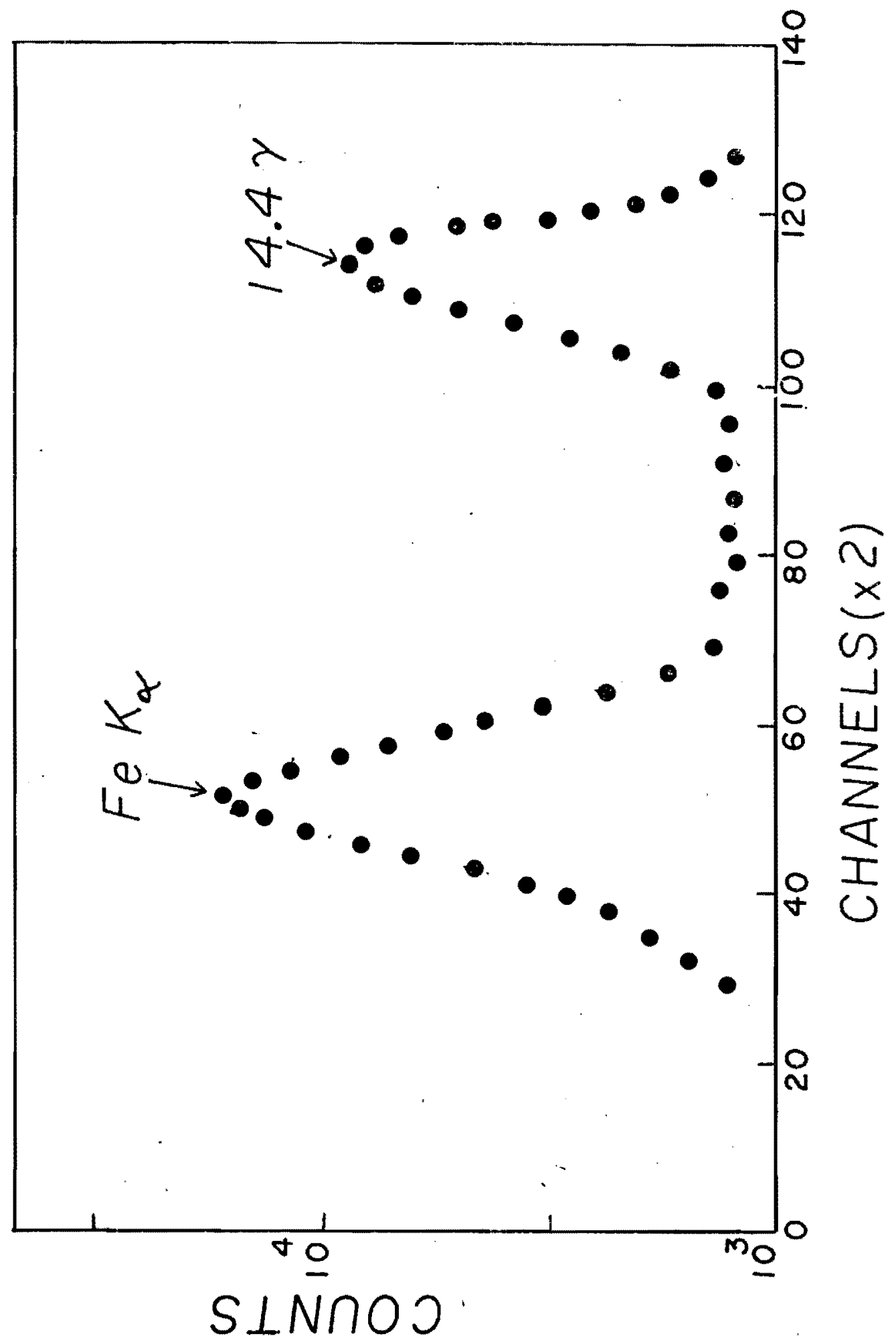

Figure 4. Fnergy spectrum of $\mathrm{Fe}^{57}$ in Aluninum 


\section{v. DATA PRESENTATION AND INTERPRETATION}

The variation of the Debye-Waller factor $f$ with temperature has been experimentally determined in the range $293 \mathrm{~K}-545 \mathrm{~K}$. The results of these measurements are shown in figure 5. The expected temperature dependence of $(-\ln f)$ on the basis of the Debye model. has also been calculated. The results of these calculations are the solid lines shown in figure 5. The method used to fit the parameters $\theta_{D}(-2)$ and $\varepsilon(-2)$ has been described in detall by Nussbaum et al. (15)

Fxamining the curve marked A in figure 5, one notices the excellent agreement between the experimentally determined value of $f$ and its theoretical counterpart in the temperature range $293 \mathrm{~K}-500 \mathrm{~K}$. Ahove $491 \mathrm{~K}$ the measured value of $\mathrm{f}$ no longer follows the predicted 11ne but is greater than that predicted by the Debye model. From equation 4 we see that $-\ln f \propto\left\langle x^{2}\right\rangle$ where, $\left\langle x^{2}\right\rangle$ is the mean squared displacement of the $\mathrm{Fe}^{57}$ impurity atoms in the Aluminum matrix. An increase in $f$ therefore, corresponds to a decrease in the value of $\left\langle x^{2}\right\rangle$. Since, the mean squared displacement depends on the local environment surrounding the impurity atom any changes in its value indicate a subsequent change in the environment. Moreover, at $545 \mathrm{~K}$, the value of $f$ is not constant but is found to increase with time (see figure 6). Based on these observations, we propose that the increase in the value of $f$ is caused by the diffusion of the $\mathrm{Co}^{57}$ 


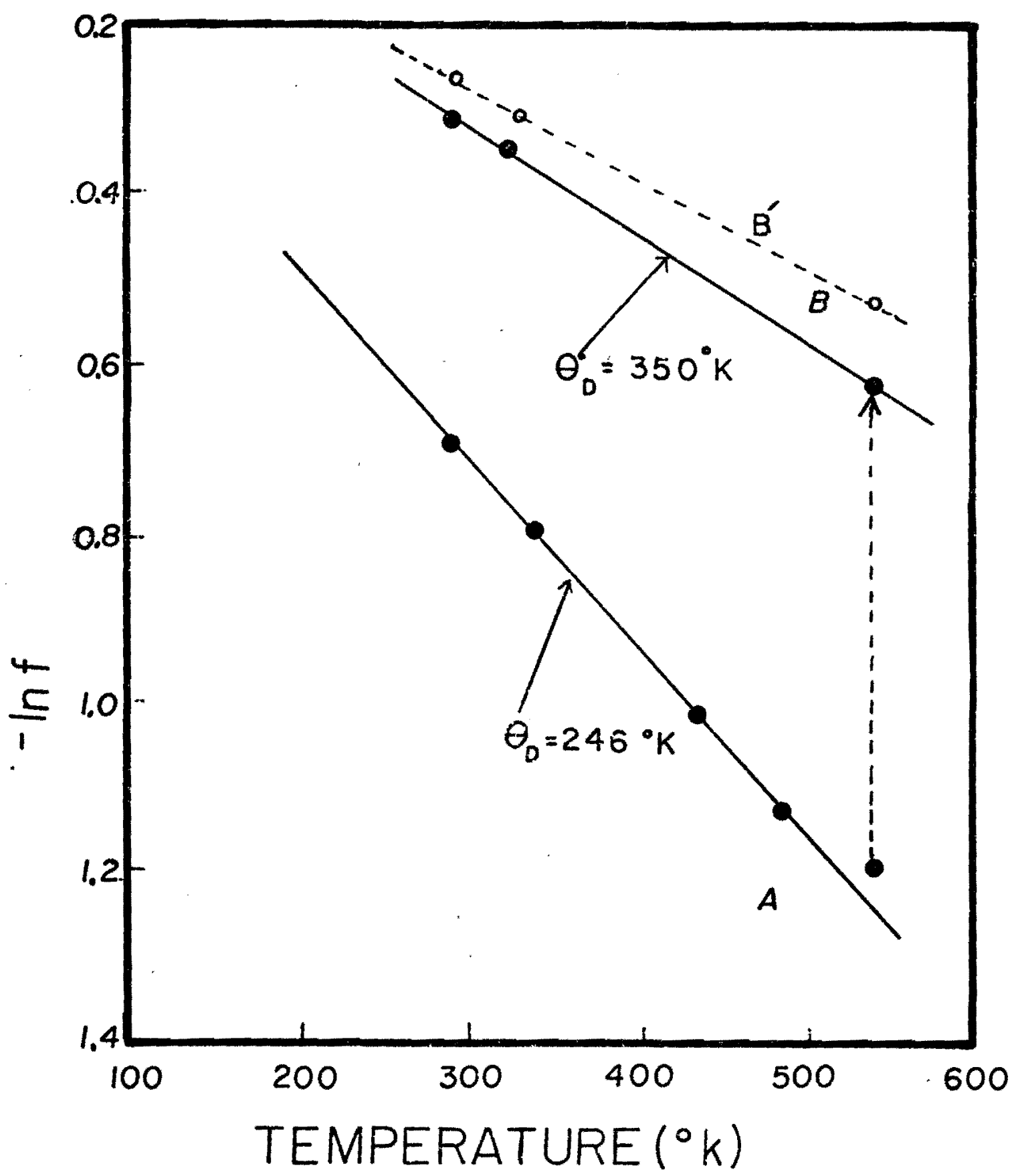

Figure 5.Temperature dependence of the Debye-Waller factor for cobalt impurity atoms in sites $A$ and $B$ respectively. 


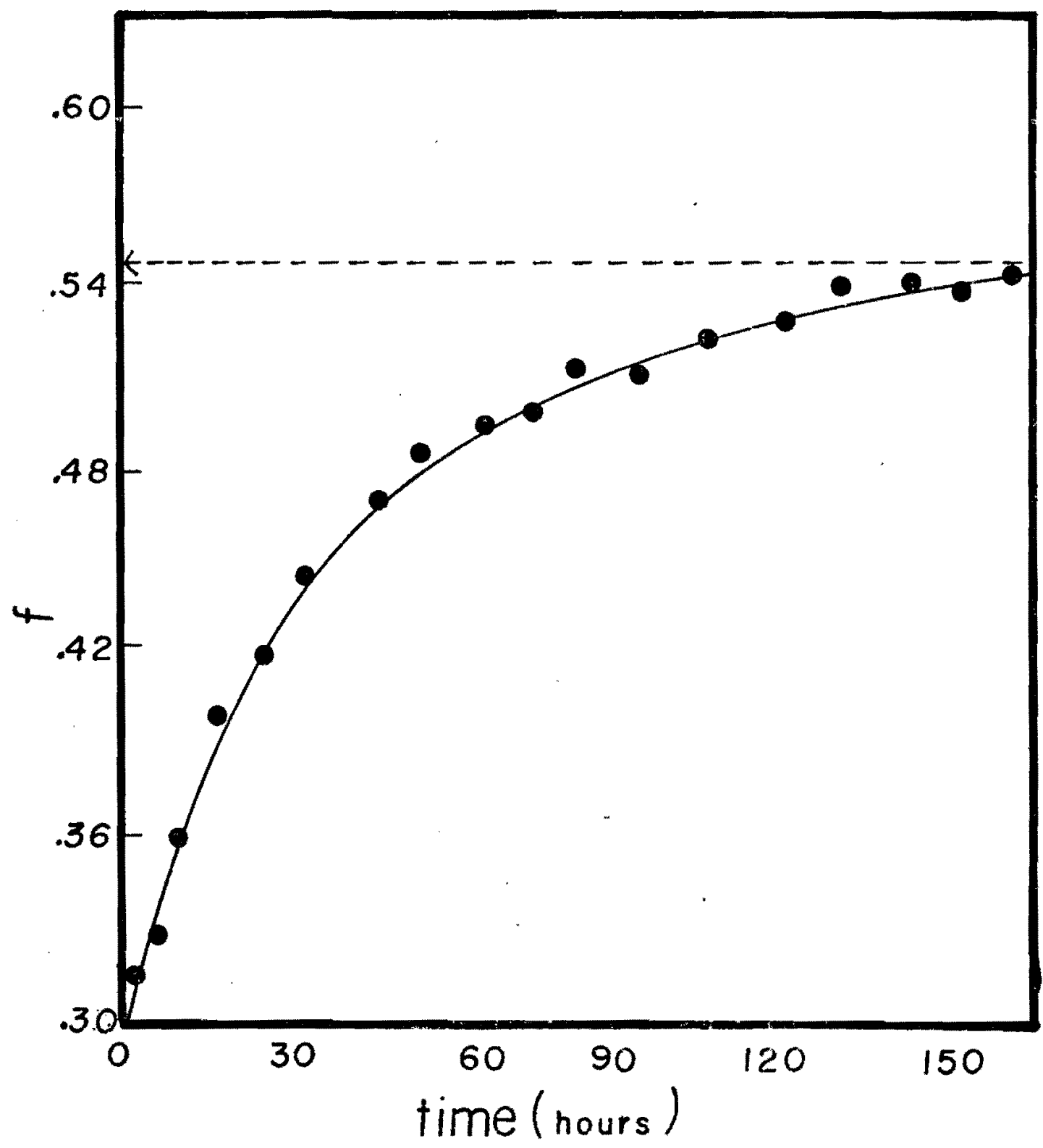

Figure 6. Time dependence of the Debye-Waller factor for $\mathrm{Co}^{57}$ at $545 \mathrm{~K}$. 
Impurity atoms from one lattice site to another, non-equivalent site which is characterized by a much higher value of the Debye-Waller factor. These two sites will be referred to in this chesis as sites $A$ and $B$ respectively. A detailed analysis of sites $A$ nad $B$ is given below :

\section{SITE A}

Annealing the sample near 1 ts melting temperature for 8-10 days results in the creation of site $A$. The temperature range used for creating this state lies between $840 \mathrm{~K}$ and $930 \mathrm{~K}$. There is no direct evidence, such as $x$-ray diffraction, etc., to indicate the type of lattice sites that the $\mathrm{Co}^{57}$ atoms could occupy in the host matrix. The atomic radius of cobalt $\left(R_{C o}=1.25 \AA\right)$ 1s about $14 \%$ less in magnitude than the radius of aluminum $\left(R_{A 1}=1.43 \AA\right)$. On the basis of size ratios, Haag's rule (18) would predict a substitutional solid solution for the Co-Al system. If cobalt atoms do occupy substitutional sites in the Al matrix, the Mössbauer spectrum should consist of a sharp, well defined single line pattern. This is so because of the following reasons :

a) There is no magnetic ordering in the phase, so there w11 be no broadening of the line due to any magnetic effects.

b) The amount of cobalt atoms is very small (approximately $10^{-4}$ at. $\%$ in the case of $A I$ II) so assuming a perfectly random distribution for the $\mathrm{Co}^{57}$ atoms, there is very little likelihood that a given cobalt atom will 


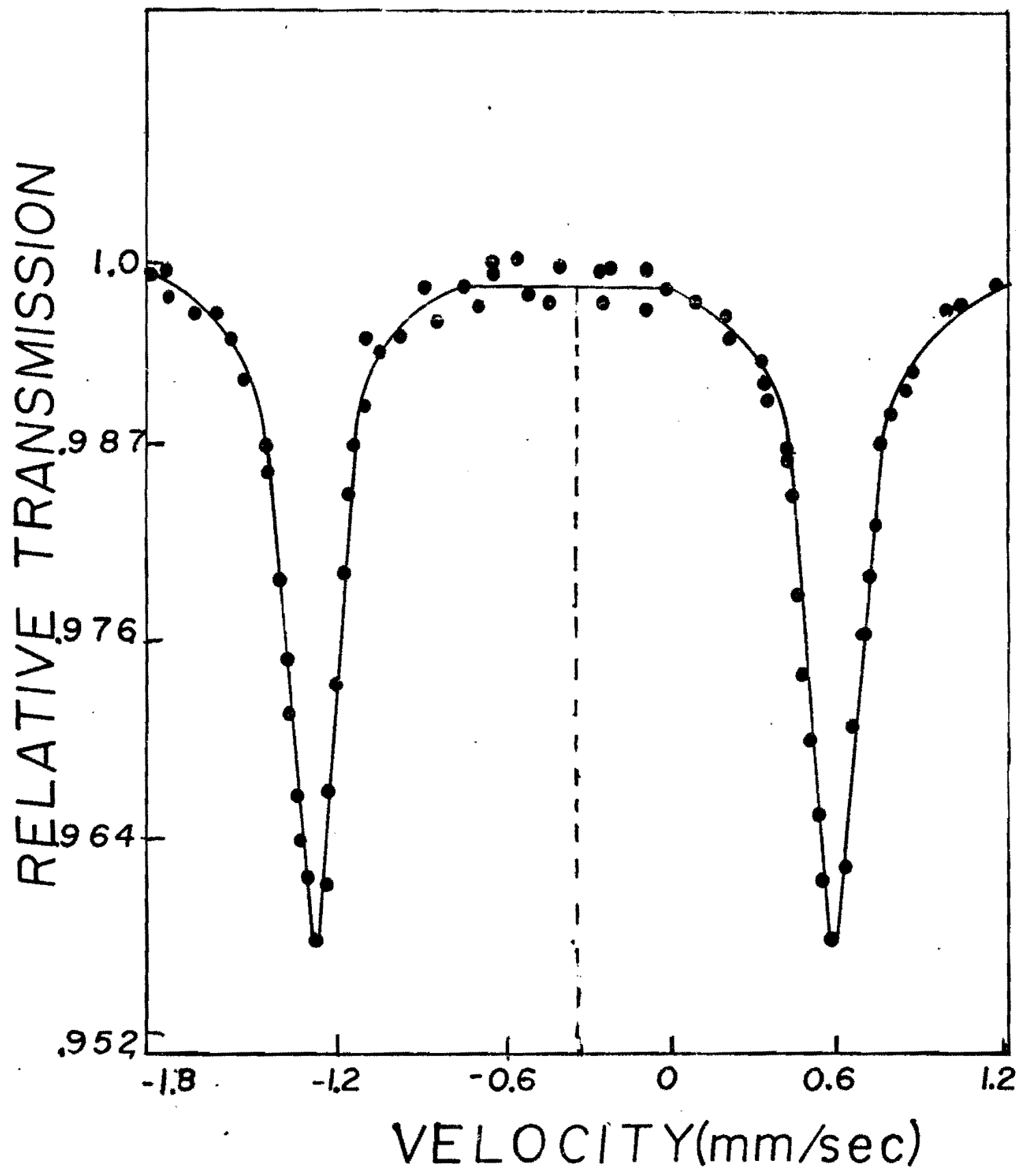

Figure 7. Mössbauer spectrum for $\mathrm{Co}^{57}$ atoms occupying site A. 
have a second cobalt atom near it to affect its Mössbauer spectrum.

c) Since the substitutional Co atoms are not quite the right size, their presence undoubtedly causes a local distortion of the host lattice. The symmetry about the Co atom w111 however remain essentially cubic and so the substitution of the cobalt atom merely introduces cubically symetric distortions. Under these clrcumstances, the Co atom experiences no electric field gradients to broaden its spectrum. The Mössbauer spectrum for $\mathrm{Co}^{57}$ atoms in site $A$, shown in figure (7) was taken after the sample (AI II) was subjected to 10 days of annealing at $898 \mathrm{~K}$. The spectrum consists of a slightly broadened single line pattern. The measured line shape parameters are listed in table (II). We have been unable to give a sultable explanation for the line broadening mentioned above as another sample (Al III) was prepared (under identical conditions to that used for A1 II) In which the site A spectrum consisted of a single line having natural width. On the basls of these line shape measurements on AI II and A1 III, we conclude that site A is substitutional in character.

The next step in the analysis of the data is to obtain values for the lattice parameters $\theta_{D}(-2)$ and $\varepsilon(-2)$ for Co atoms in the substitutional site. It must be noted that since beyond $500 \mathrm{~K}$ a significant number of Co atoms have diffused from the substitional 
TABLE II

LINE SHAPE AND LATTICE DYNAMICAL

PARAMETERS FOR IRON ATOMS

OCCUPYING SITE A

\begin{tabular}{|c|c|c|c|c|c|}
\hline $\begin{array}{l}\text { \# } \\
\text { ISOMER } \\
\text { SHIFT } \\
\delta \\
(\mathrm{mm} / \mathrm{sec})\end{array}$ & $\begin{array}{l}\text { LINE } \\
\text { WIDTH } \\
r \\
(\mathrm{~mm} / \mathrm{sec})\end{array}$ & $\begin{array}{c}\text { DEBYE TEMP } \\
\text { (Fe) } \\
\theta_{D}(-2)\end{array}$ & $\begin{array}{l}\text { ** } \\
\text { DEBYE TEMP } \\
\text { (Al) } \\
\theta_{\text {host }}\end{array}$ & $\begin{array}{l}\text { ANHARM. } \\
\text { PARAMETER } \\
\qquad(-2) \\
(\mathrm{K})^{-1}\end{array}$ & $\begin{array}{l}\text { FORCE } \\
\text { CONSTANT } \\
\text { RATIO } \\
\alpha^{\prime} / \alpha\end{array}$ \\
\hline-0.421 & 0.230 & $246.1 \mathrm{~K}$ & $396.0 \mathrm{~K}$ & $\sim 0.0$ & $\sim 0.80$ \\
\hline
\end{tabular}

* Relative to natural Iron

** Value taken from reference (22) 
site to site $B$, as is evident from the anamolous increase in the value of $f$ (see figure 5). Therefore, the data above $500 \mathrm{~K}$ cannot be used to determine $\theta_{D}(-2)$ and $\varepsilon(-2)$. Table (II) 1ists the values obtained for these lattice parameters.

\section{SITE B}

Annealing the sample for 8 - 10 days between $545 \mathrm{~K}$ and $780 \mathrm{~K}$ results in the formation of $\mathrm{Co}^{57}$ atoms occupying site $B$. Site $B$ can be readily distinguished from the substitutional site $A$ on the basis of the following characteristics:

a) Non-cubic symmetry - Co atoms in site B have a non-cubic environment. This is clearly revealed by the Mössbauer spectrum taken after the sample was annealed for 9 days at $706 \mathrm{~K}$. The spectrum is shown in figure 8. The line shape is characterized by a well defined quadrupole doublet with the two peaks being equal in intensity, thereby Indicating the existence of an electric field gradient at the site of the Co Impurity. The line shape parameters have been 11sted in Table III.

b) Increase in s-electron density - the Isomer shift relative to natural Iron for the impurity atoms in site $B$ is less in magnitude than that in site $A$. This corresponds to an Increase in s-electron density for $\mathrm{Fe}^{57}$ atoms in site $\mathrm{B}$. Using the 'Walker Chart' (see Appendix A), the electronic configuration for 


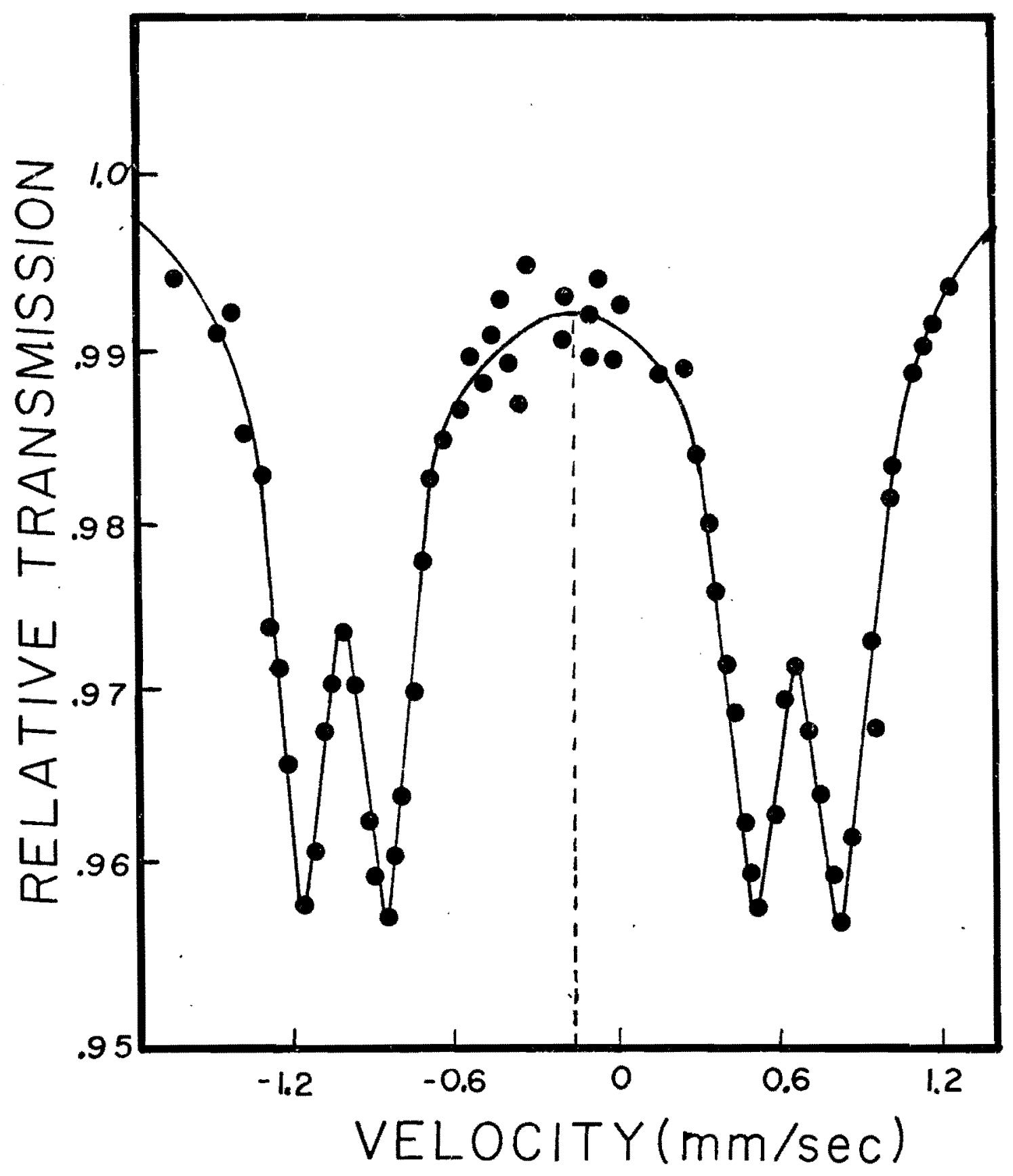

Figure 8. Mössbauer spectrum for $\mathrm{Co}^{57}$ atoms occupying site $B$. 
Iron atoms in site $B$ can be written as $3 d^{7} 4 s^{0.95}$. The corresponding electronic configuration for site A impurity atoms can be written elther as $3 d^{7} 4 s^{0.72}$ or $3 \mathrm{~d}^{7.15} 4 \mathrm{~s}^{0.85}$. The 1mportance of this data is not, however, yet fully understood, mostly because the theory of metals and alloys has not been sufficlently developed. However, isomer shifts may prove to be a useful tool for investigating the environments surrounding the impurity atoms.

c) Tight binding - f-measurements on Al II (with $\mathrm{Co}^{57}$ atoms in site B) reveal that the mean squared displacement is much smaller compared to that for site $A$, under identical temperature conditions. This is clearly seen in curve $B$ (figure 5) which represents the temperature dependence of $f$ with $90 \%$ of the Impurity atoms in site $B$ (insufficient annealing at $545 \mathrm{~K}$ resulted in this partial transformation of cobalt atoms from site $A$ to site $B$ ). We have corrected for the incomplete transformation and the results of this calculation is the curve marked $B$ in figure (5). Analyzing the data shown in figure (5) we find the Debye temperature $\theta_{D}(-2)$ to be much higher than that for site A. The various lattice parameters derived from $f$-measurements have been listed in Table III. To fully understand the nature of the crystal environment which produces 
TABLE III

LINE SHAPE AND LATTICE DYNAMICAL

PARAMETERS FOR IRON ATOMS

OCCUPYING SITE B

\begin{tabular}{|c|c|c|c|c|c|}
\hline $\begin{array}{l}\text { * } \\
\text { ISOMER } \\
\text { SHIFT } \\
\quad \delta \\
(\mathrm{mm} / \mathrm{sec})\end{array}$ & $\begin{array}{l}\text { LINE } \\
\text { WIDTH } \\
\Gamma \\
(\mathrm{mm} / \mathrm{sec})\end{array}$ & $\begin{array}{l}\text { QUAD. } \\
\text { SPLITTING } \\
\qquad \begin{array}{l}\Delta E \\
(\mathrm{~mm} / \mathrm{sec})\end{array}\end{array}$ & $\begin{array}{c}\text { DEBYE TEMP. } \\
(\mathrm{Fe}) \\
\theta_{\mathrm{D}}(-2)\end{array}$ & $\begin{array}{l}\text { ANHARM. } \\
\text { PARAMETER } \\
\qquad \begin{array}{c}\text { (-2) } \\
(\mathrm{K})^{-1}\end{array}\end{array}$ & $\begin{array}{l}\text { FORCE } \\
\text { CONSTANT } \\
\text { RATIO } \\
\qquad \frac{\alpha^{\prime}}{\alpha}\end{array}$ \\
\hline-0.150 & 0.210 & 0.279 & $\sim 350.0 \mathrm{~K}$ & $\sim 0$ & -1.60 \\
\hline
\end{tabular}

* Relative to natural Iron 
site B, a number of quenching experiments were performed on Al II.

By this procedure it is possible to 'freeze-in' a hjgh temperature state, and yet examire the Mösshauer effect at room temperature where the Debye-waller factor, and hence the total fraction of recoiless gamma rays emitted is large. We started these measurements with the impurity atoms all in site B (after a long anneal at $545 \mathrm{~K}$ ), and then re-annealed the sample at a number of temperatures lying between $545 \mathrm{~K}$ and $898 \mathrm{~K}$ long enough to establish a new equilibrium configuration. After a rapid quench (assuming that no changes occurred in the impurity distribution) we determined the room temperature value of the Debye-Waller factor. The times required to reach equilibrium at each annealing temperature was approximately of the order of 8 to 10 days. The results of these f-measurements are shown in figure (9), where we have plotted $K(T)$ as a function of the annealing temperature $T$. $K(T)$ is the fraction of site B impurity atoms and has been defined as follows:

15) $K(T)=\frac{f_{\exp }-f_{A}}{f_{B}-f_{A}}$ where $f_{\text {exp }}$ is the room temperature measured after quenching $A l$ II from a temperature $T$ and $f_{A}$ and $f_{B}$ are the $f$ values (at room temperature) for sites $A$ and $B$ respectively. For $K(T)=1$, we have all the $\mathrm{Co}^{57}$ atoms occupying site $B$ in the host natrix and for $K(T)=0, a 11$ the atoms are In site $A$. For the case, $0<K(T)<1$, which results when Al II is quenched from temperatures between $760 \mathrm{~K}$ and $825 \mathrm{~K}$, the measured Iine shape is a mixture of a single line pattern and a quadrupole doublet (see figure 10) 


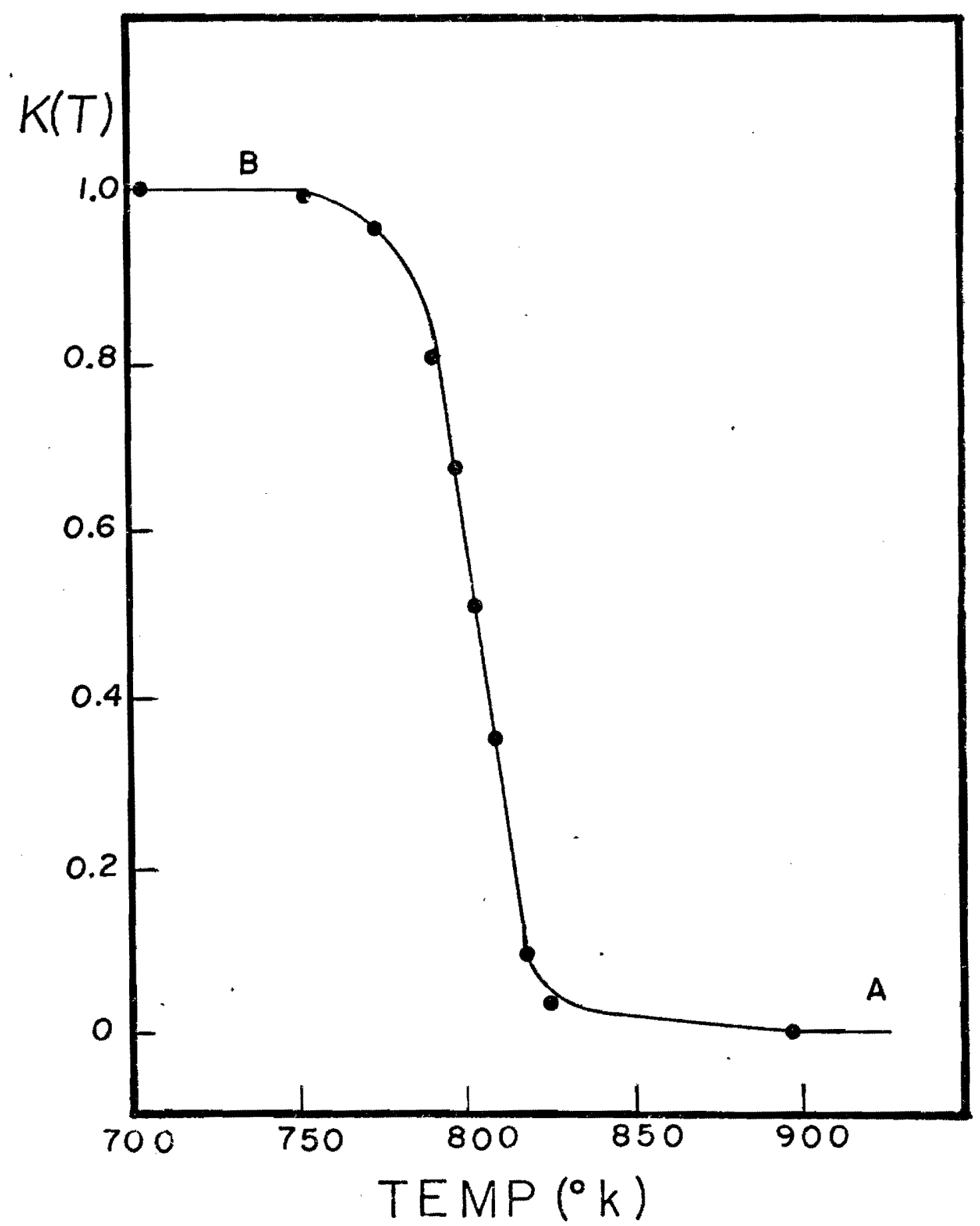

Figure 9. Temperature dependence of $K(T)$. 


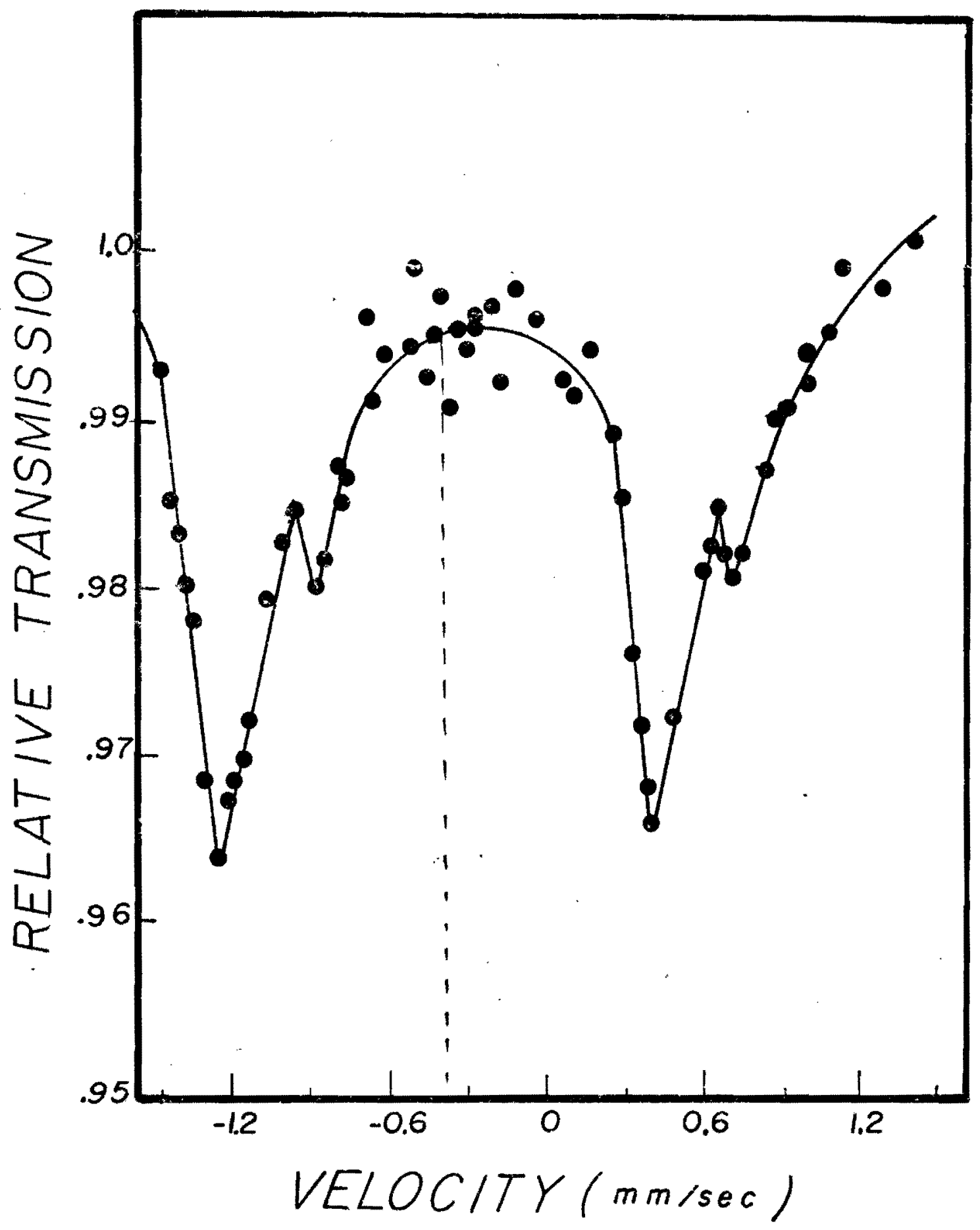

Tigure 10. Mossbauer spctrum taken after annealing A1 II at $793 \mathrm{~K}$ for 3 days. 
characteristic of the co-existence of the two sites. We can therefore conclude that the two impurity sites are independent and that there exists a temperature dependent equilibrium of thelr concentrations. Based on these observations we propose the following two models for site $B$ :

MODEL I. The impurity atoms could be paired off in the form of dumbbells (split $<100>$ interstitials), as in the case of $\mathrm{Co}^{57}$ in gold $(21,17)$. Since this model requires two impurities to be in the nearest neighbor positions before such a pair can be formed, the dependence on diffusion enters the picture quite naturally. If the atoms are assumed to be hard spheres with the dlameter given by the nearest nelghbor spacing of the metal (see Fig. 11), it is possible to determine the size of the hole created by removing one of the Al atoms. This hole is too small to accommodate two cobalt atoms. More room can be created for the palr by forming these dumbbells in dislocations or by distributing a vacancy among the $A l$ atoms surrounding the palr. The Mössbauer spectrum for site $B$ (Figure 8 ) does not reveal any excessive line broadening, Indicating the absence of $\mathrm{Co}^{57}$ atoms in dislocations. This favors the view that a formation of a dumbbell requires the presence of vacancles amongst the Al atoms close to the pair. This distribution of vacancies coupled with the slow diffusion of co in Al could explain the long times involved in creating site B. Th1s model gives a satisfactory explanation for both the quadrupole splitting and high f's observed for site B. In this configuration the Impurity atoms occupy positions which lack cubic symmetry, thereby creating a non-zero electric field gradient (at the 


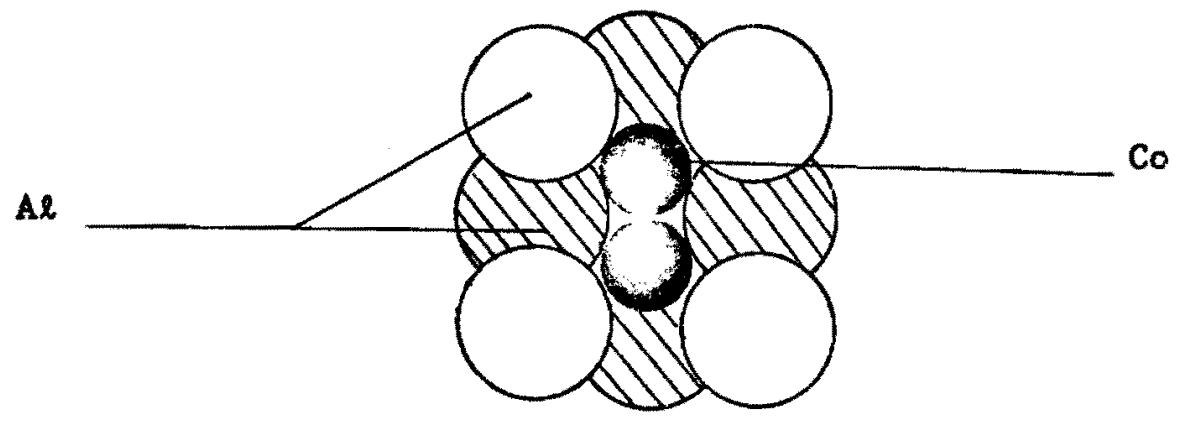

Figure 11. Position of the 1mpurity dumbbell in the Al lattice. The symmetry axis of the dumbbell can lie along any of the three [100] directions. 
site of the Co atom). In addition the crowding effect experienced by the Impurity atom (In the dumbbell configuration) w111 result in a mean squared displacement much smaller in magnitude than that for the impurity atom in a substitutional site. There is one major drawback to this model: it fails to predict the slow times involved in breaking up dumbbel1s. So far, all attempts to modify the theory in order to account for the slow break up time have met with little success.

MODEL II. The Impurity atoms could be a part of an Intermetallic phase that precipitates out of the solld solution. From the Co-Al phase diagram, one expects co to precipitate out as the intermetallic compound $\mathrm{CoAl}_{3}$ (26). $\mathrm{CoAl}_{3}$ has a monoclinic structure (3) with 100 atoms per unit ce11 and five different types of Co atom environment. Since each type of co atom environment should have a characteristic Mössbauer spectrum, one would expect a complicated line shape for this phase (6). The Mössbauer line shape for site $B$ is however Indicative of only one type of Co atom environment, therefore ruling out the possibility that the precipitate formed is $\mathrm{CoAl}_{3}$. However, Co may very well be precipitating out in the form of some other intermetallic compound.

An alternate view is to consider the possibility of the formation of small clusters of co within the host matrix. The screened potential around a Co atom in $\mathrm{A} 1$, is given by the expression (25): 
16) $V(R)=\frac{z \pi e \operatorname{Cos}\left(2 k_{F} R-\delta\right)}{k_{F}^{2} R^{3}}$

$V(R)$ is the electrostatic potential at a distance $R$ from the impurity atom and $k_{F}$ the Fermi wave number for aluminum. This potential has been plotted in figure (1.2) and shows the existance of an attractive force between Co atoms at nearest nelghbor distances. Co atoms therefore have a tendency to cluster and possibly form Guinier-Preston zones (see Appendix B).

The formation of a new phase (whether an inter-metallic ppt. or Co clusters) involves the process of nucleation (24). The latter in turn, depends on the following three steps (25):
a) Assembly of the proper kind of atoms by diffusion.
b) Structural change into one or more intermediate structures.
c) Formation of the new phase.

Due to the low solubility of Co in aluminum, step (a) is very slow. The slowness of step (a) couvled with steps (b and c), which are also time dependent (24), can explain the long times needed to form site B. Simllarly, the break up of these clusters (or preclpitates) Is* slow.

Model II, on the other hand cannot give a satisfactory explanation for the high f's and observed line shape splitting as we have no direct Information regarding the exact structure of this new phase.

\footnotetext{
* From the classical nucleation theory, the break up is analogous to the slow evaporation of atoms from the surface of a 11quid drop.
} 


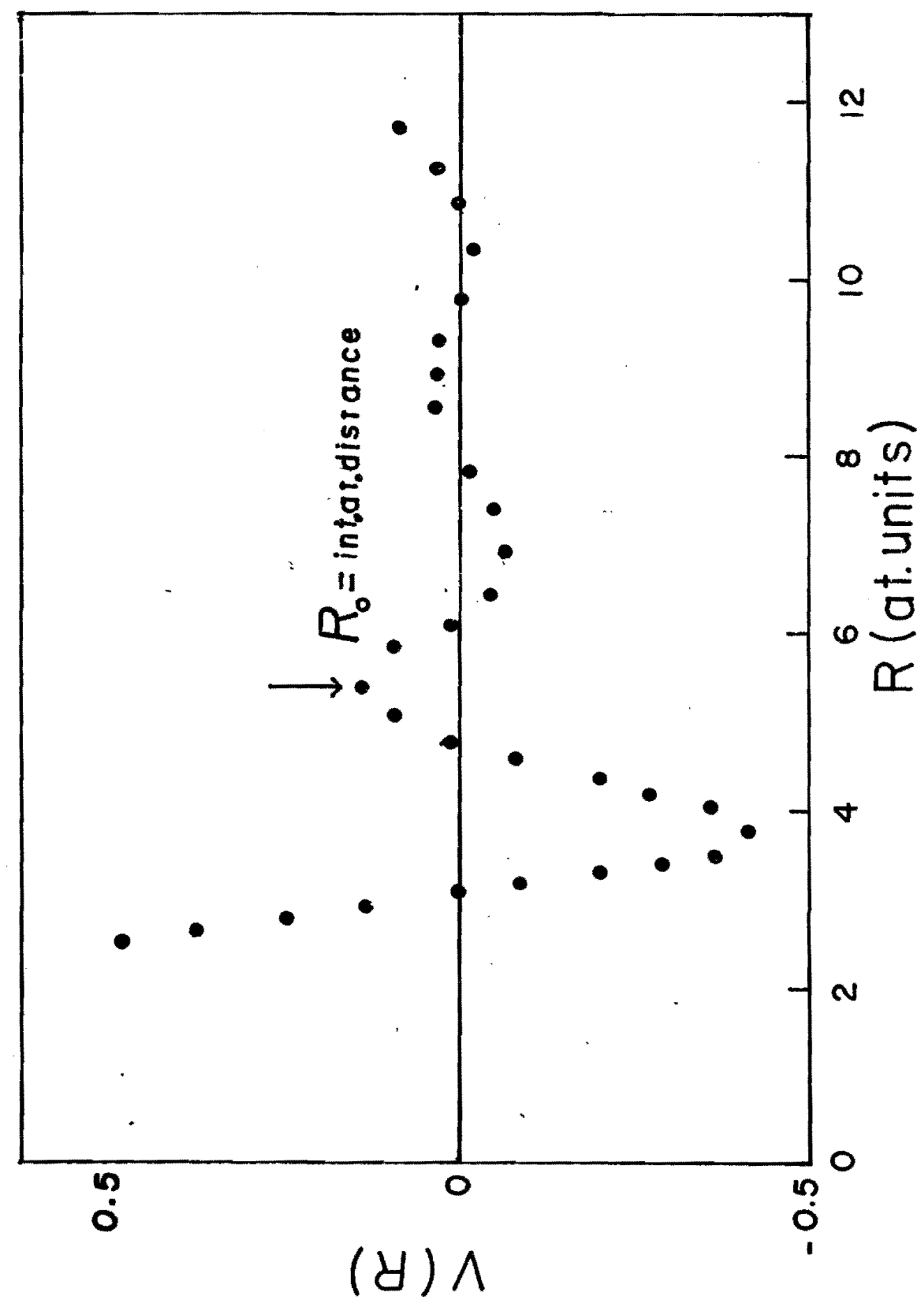

Figure 12. Electrostatic potentlal per unit positive charge about an Co atom in an Al matrix. 
VI. SUMMARY AND CONCLUSIONS

Using Mössbauer spectroscopy, two distinct lattice sites occupled by Co $\left(10^{-4}\right.$ at. $\left.\%\right)$ in Aluminum have been isolated and tentatively identifled. The substitutional site A is the stable position after annealing a dilute alloy above $840 \mathrm{~K}$ for a perlod of 8 - 10 days. Co atoms in site A are characterized by a single line Mössbauer spectrum and a room temperature $f=0.502$. Annealing below $770 \mathrm{~K}$ for $8-10$ days results in the migration of the Impurity atoms to site $B$. This site is characterized by a weil defined quadrupole doublet (Indicative of a non-cublc environment) and a much higher value for the Debye-Waller factor $(f=0.766)$. The site distribution A / B varles from $95 \%$ to $5 \%$ for anneals between $770 \mathrm{~K}$ and $825 \mathrm{~K}$. All linewidths are approximately $0.21 \mathrm{~mm} / \mathrm{sec}$, indicating a high untformity of impurity sites in the host matrix.

Two possible models for site $B$ have been proposed in this thesis. Model I, considers the impurity atoms to be in the form of dumbbells (split <100> Interstitials). In such a configuration, two $\mathrm{Co}^{57}$ atoms are crowded into the same substitutional site. The impurity atom therefore has a non-cubic environment (resulting in the observed splitting of the spectrum) and the crowding effect causes a decrease in the mean squared displacement of the Co atom (or increase in $F$ ). In addition, the formation of a dumbbell is directly related to the diffusion of Co atoms in Al. As the diffusion of Co below $770 \mathrm{~K}$ is 
very slow, the formation of site $B$ is a slow process (as borne out by observations). However, the model falls to account for the slow break-up rate of site $B$.

In model II, the Co impurity atoms are assumed to be in the form of either an intermetallic precipitate or Guinier-Preston zones. Such a model is capable of explaining (on the basts of the classical nucleation theory) the slow rate of formation and break-up of site $B$. On the other hand, due to lack of information regarding the structure of these precipitates (or zones) it is uncertain whether they can explain the observed line splitting and high $\mathrm{f}^{\dagger} \mathrm{s}$.

As yet, we are unable to choose between the two models. A number of experiments are in progress which might shed more light on the precise nature of site $B$. Recently, we have prepared a more concentrated alloy of cobalt $\left(10^{-2}\right.$ at. \% Co $)$ in Al. Preliminary measurements made on this alloy reveal the presence of only one type of impurity site, namely site $\mathrm{B}$ at all temperatures below $832 \mathrm{~K}$. This is at variance with the absorber experiments conducted by Bush et al (3) on an alloy of iron $\left(5 \cdot 10^{-2}\right.$ at. $\left.\% \mathrm{Fe}\right)$ in $\mathrm{Al}$, which clearly shows the existence of two impurity sites (identical to site $A$ and site $B$ ). This difference in the results of the source and absorber measurements indicate that, although one studies the nuclear physics of iron in both type of measurements (source and absorber), the metallurgy involved may be quite different. Source measurements involve the metallurgy of the Co-Al system, whereas absorber work is concerned with the Fe-Al system. Therefore, we feel that a portion of the inconsistancy in the results of previous workers $(1-6)$ could be explained by the difference between source and absorber measurements mentloned above. 
TABLE IV

SUMMARY OF DATA FOR SITES A AND B OCCUPIED BY $\mathrm{CO}^{57}$ IN Al

\begin{tabular}{|c|c|c|c|c|c|c|c|}
\hline $\begin{array}{l}\text { LATTICE } \\
\text { SITE }\end{array}$ & $\begin{array}{l}\text { * } \\
\text { ISOMER SHIFT } \\
\qquad \\
(\mathrm{mm} / \mathrm{sec})\end{array}$ & $\begin{array}{l}\text { QUADRUPOLE } \\
\text { SPLITTING } \\
\Delta E \text { (mm/sec) }\end{array}$ & $\begin{array}{c}\text { LINE WIDTH } \\
\Gamma \\
(\mathrm{mm} / \mathrm{sec})\end{array}$ & $\begin{array}{c}\text { DEBYE TEMP } \\
(\mathrm{Fe}) \\
\theta_{\mathrm{D}}(-2)\end{array}$ & $\begin{array}{l}\text { REL. } \\
\text { FORCE } \\
\text { CONST. } \\
\dot{\alpha} / \alpha\end{array}$ & $\begin{array}{c}\text { MÖSSBAUER } \\
\text { FRACTION } \\
\mathbf{f}\end{array}$ & $\begin{array}{l}\text { MEAN SQUARE } \\
\text { DISPLACEMENT } \\
\left\langle\mathrm{x}^{2}\right\rangle \AA^{2}\end{array}$ \\
\hline $\mathbf{A}$ & -0.421 & - & 0.230 & $246.0 \mathrm{~K}$ & $\sim 0.80$ & $\begin{array}{r}0.502 \\
\pm 0.001\end{array}$ & 0.013 \\
\hline B & -0.150 & 0.279 & 0.210 & $350.0 \mathrm{k}$ & $\sim 1.60$ & $\begin{array}{r}0.766 \\
\pm 0.001\end{array}$ & 0.005 \\
\hline
\end{tabular}

* Isomer shifts quoted in table are with respect to natural iron. 


\section{BIBLIOCRAPHY}

1. J. Bara, H. U. Hyrnkiewicz, A. Z Hyrnkiewicz, M. Karapandzic and T. Matlak, Phys. Status Solldi 17, K 53 (1966)

2. G. D. Sprouse, G. M. Kalvius and S. S. Hanna, Phys. Rev. Letters 18, 1041 (1967)

3. R. H. Bush, C. A. Stickels and L. W. Hobbs, Scripta Met. 1. 75 (1966)

4. C. Janot and G. Lelay, Compt. Rend. 269 B, 823 (1969)

5. S. Nasu, M. Nishio, Y. Tsuchida, Y. Murakami and T. Shinjo, J. Phys. Soc. Japan 27, 1363 (1969)

6. R. S. Preston and R. Gerlach, Phys. Rev 3, 1519 (1971)

7. H. Frauenfelder, "The Mossbauer Effect ", (W. A. Benjamin, 1963)

8. H. J. Lipkin, Ann. Phys. 9, 332 (1960)

9. R. H. Nussbaum, "Mössbauer Effect Me thodology Vo1.2, ( Plenum Press, N. Y., 1966)

10. A. A. Maradudin and P. F. Flinn, Phys. Rev 129, 2529 (1963)

11. C. K. Wertheim, "Mössbauer Effect ", (Acadenic Press, N.Y., 1971)

12. W. L. Nees, M. S. Thesis, Portland State University, 1968 (unpublished)

13. R. M. Housley, N. E. Ericson and J. G. Dash, Nucl. Instr, and Methods, 27, 29 (1964)

14. R. M. Housley, Nucl. Instr, and Methods 35,77 (1965)

15. R. H. Nussbaum, D. G. Howard, W. L. Nees and C. F. Steen, Phys. Rev. 173, 653 (1968)

16. W. M. Visscher, Phys.Rev. 129, 1 (1963)

17. C. F. Steen, M. S. Thesis, Portland State University, 1971 (unpublished) 
18. I. R. Anthony and D. iiurn'sull. Phys. Rev. 151, 495 (1966)

19. R. Tuusley and F. Hess, Phys. Rev. 146, 517 (1966)

20. L. R. Waiker, G. K. Wertheim and V. Jacarino, Phys. Rev. Letters 6. 98 (1961)

21. C. F. Stein, D. G. Howard and R. H. Nussbaum, Solid State Comm. ( to be published)

22. C. Gilat and R. M. Nicklm, Phys. Rer. 143, 1487 (1966)

23. R. W. Cahn, "Physical Metallurgy ", (North Holland Publishing . Company, 1965)

24. J. H. Brophy, R. M. Rose and J. Wulff, "The Structures and Properties of Materials, Vol.II ", (John Wiley and Sons, I967)

25. G. M. Hood, Phil. Mag. 21, 305 (1970)

26. M. Hansen and K. Anderko, "Constitution of Binary Alloys ", ( McGraw - Hill, N. Y. 2958) 


\section{APPENDIX A}

\section{WALKER CHART}

Isomer shifts have been measured in various host materials and a large amount of information has been obtained for metals and alloys. Walker et al (20) reported the information of the $\mathrm{Fe}^{57}$ isomeric shift in various solids relative to stainless steel in the form of the "Walker Chart". In this chart the total s-electron density is plotted as a function of the percentage of $4 \mathrm{~s}$ character for various $3 \mathrm{~d}$ electron configurations. In order to interpret the observed isomeric shift according to the "Walker Chart", it is necessary to convert from the value relative to iron to that relative to stainless steel. The value of $\mathrm{Fe}^{57}$ isomeric shift in iron relative to stainless steel is known to be about $0.09 \mathrm{~mm} / \mathrm{sec}$. Therefore, the value of the isomeric shift in Al relative to stainless steel will be given by:

18) I.S. (St.) = I.S. (Fe) +0.09

where I.S. (Fe) Is the measured Isomer shift relative to natural iron. Once the isomer shift (rel. to S.S.) is known, the corresponding electronic configuration can be directly read off from the chart. 
APPENDIX B

\section{GUINIER-PRESTON ZONES}

The Ideal Guinier-Preston zone is a region of the matrix with high solute concentration, but in which all the atoms are situated on the sites occupied in the random solid solution. A zone has a different composition and may have differing interatomic distances from those of the matrix, but its structure is continuous with that of the matrix. These clusters are generally small (consisting of a few atoms) and may be either flate shaped or spherical depending on the extent of the change produced in the lattice parameter (of Al) by the addition of the solute ator.

Nearly Ideal zones with no deformation of the surrounding lattice are found in alloys of aluminum with silver or zinc. More usually, the size difference of the solute and solvent atoms will produce some distortions, and the atoms In and around the zone will be displaced from their positions in the random solid soiution. It is characteristic of a cluster or zone, as distinct from a coherent precipitate, that the atom sites do not approximate to a new regular arrangement under these clrcumstances; the displacements may be regarded as large elastic strains and vary from the center to the outside of the zone.

Direct images of Guinier-Preston zones has been obtained using electron microscopy and x-ray diffraction. The diffraction technique 
has one major drawiock, that is, it requires a minimum concentration of the solute atoms (normally $2 \%$ ). On the other hand, electron mtcroscopy can detect these zones in aljoys having solute concentration as low as $0.05 \%$. 